\title{
Análise da verticalização urbana no eixo estruturador de Passo Fundo - RS
}

\author{
Analysis of urban verticalization in the structuring axis of Passo Fundo - RS
}

Evanisa Fátima Reginato Quevedo Melo[a] (ㄱ), Sidnei Matana Júnior [b] (1)

[a] Universidade de Passo Fundo (UPF), Faculdade de Engenharia e Arquitetura, Passo Fundo, RS, Brasil

[b] Universidade de Passo Fundo (UPF), Programa de Pós-graduação em Engenharia Civil e Ambiental, Passo Fundo, RS, Brasil

Como citar: Melo, E. F. R. Q., \& Matana Júnior, S. (2020). Análise da verticalização urbana no eixo estruturador de Passo Fundo - RS. urbe. Revista Brasileira de Gestão Urbana, 12, e20190369. https://doi.org/10.1590/21753369.012.e20190369

\section{Resumo}

O processo de verticalização das cidades produz impactos que beneficiam ou prejudicam a qualidade do espaço urbano, sendo assim, analisar os seus desdobramentos constitui uma ferramenta no planejamento das cidades. 0 objetivo do estudo foi analisar o processo de verticalização no eixo estruturador da cidade de Passo Fundo, no norte do Rio Grande do Sul. 0 estudo compreendeu a análise de um trecho de 7,62km, sendo os levantamentos in loco realizados em duas etapas, a primeira em 2013 e a segunda em 2018. Os dados coletados são referentes ao gabarito de altura e à presença ou ausência de recuos prediais nas edificações. Os levantamentos apontaram o crescimento no número de edificações, em especial as edificações com mais de 13 pavimentos, cerca de 78\%; também foi apontado o crescimento de $17 \%$ das edificações com recuos frontais e/ou laterais, em relação ao primeiro levantamento. A Avenida Brasil segue sua tendência histórica de verticalização, induzida pelos instrumentos de planejamento e pelo setor imobiliário, ao substituir tipologias de gabarito baixo e sem recuos por gabaritos altos com presença de recuos, mantendo a característica comercial e retomando a característica residencial através de edificações de uso misto, contribuindo assim com a criação de uma cidade compacta.

Palavras-chave: Verticalização. Densidade urbana. Plano Diretor. Morfologia urbana.

\section{Abstract}

The process of verticalization of cities produces impacts that benefit or hinder the quality of urban space, in this way analyzing their developments is a tool for city planning. The objective of the present study was to analyze the verticalization process in the structuring axis of the city of Passo Fundo, in the north of Rio Grande do Sul. This study comprised the analysis of a $7.62 \mathrm{~km}$ stretch, with surveys carried out in two stages, the first in 2013 and the second in 2018. The data collected refer to the building height

EFRQM é engenheira florestal e agrônoma, mestre em Ciência do Solo e doutora em Agronomia, professora titular, e-mail: evanisa9@gmail.com

SMJ é arquiteto e urbanista, especialista em Design e Interiores e mestrando em Engenharia Civil e Ambiental, e-mail: sidneimatana@gmail.com 
and the presence or absence of building setbacks in constructions. The surveys pointed to an increase in the number of buildings, especially buildings with more than 13 floors, about 78\%, the growth of $17 \%$ of buildings with frontal and/or lateral setbacks was also pointed out, in relation to the first survey. Avenida Brasil follows its historic trend of verticalization, induced by the planning instruments and the real estate sector, by replacing low-gauge typologies with no setbacks with high-gauge ones with the presence of setbacks, maintaining the commercial characteristic and resuming the residential characteristic through buildings of mixed use, thus contributing to the creation of a compact city.

Keywords: Verticalization. Urban density. Master Plan. Urban morphology.

\section{Introdução}

O cenário de desenvolvimento econômico, em especial na construção civil, tem provocado historicamente o crescimento da densidade e a verticalização da área urbana de Passo Fundo, cidade do norte gaúcho. É necessário compreender esse fenômeno no espaço urbano, seus impactos positivos e negativos e também como os instrumentos de planejamento urbano contribuem para este processo, a fim de estabelecer políticas urbanas que promovam o desenvolvimento sustentável das cidades. Conforme Barros \& Carriço (2019), as análises morfológicas do meio urbano permitem identificar as relações entre fenômenos sociais e a forma da cidade, os seus fatos geradores, bem como corrigir distorções e ideologias arraigadas e difundidas na sociedade.

A verticalização produz impactos no meio urbano, sejam eles positivos ou negativos. Para Jourda (2013), as altas taxas de ocupação do solo, têm tornado o meio urbano estéril, ao suprimir áreas verdes, reduzindo benefícios como captura de partículas, melhoria da qualidade do ar e a influência na ambiência urbana através da temperatura e umidade. Para Keeler \& Burke (2010), as consequências da dispersão urbana para o meio ambiente, dadas a supressão da zona rural em detrimento da zona urbana, a extração dos recursos naturais, a distância entre os locais de moradia e de trabalho, os fluxos de migração, o aumento das redes de infraestrutura, que, entre outros processos, impactaram diretamente a produção da paisagem, foram acentuadas pela velocidade em que ocorreram. Segundo Vargas \& Araujo (2014), o processo de verticalização das cidades no Brasil está associado ao conceito de progresso desde seu princípio, ainda na década de 1940, com o surgimento das incorporadoras e construtoras, beneficiadas pelas políticas habitacionais e econômicas. Cabe salientar que o processo de migração do meio rural para o meio urbano foi impulsionado pela demanda imobiliária e pelo poder de compra, os quais definiram a ocupação dos melhores terrenos, nas melhores localizações.

Para Leonelli \& Campos (2018), no Brasil, o crescimento das cidades regula-se por ações públicas e privadas, mas especificamente pela legislação urbana, pelos gestores públicos e pelo mercado imobiliário. Dentro do processo de expansão das cidades, considera-se como ideal que o planejamento municipal induza o mercado imobiliário a atuar de maneira consoante com as demandas coletivas, de tal maneira a seguir diretrizes urbanas que abordam a cidade como um todo, ao invés de áreas específicas. Neste contexto, os estudos da morfologia urbana produzem dados para subsidiar políticas de planejamento voltadas à produção sustentável da cidade; ao compreender sua evolução, é possível traçar estratégias a partir dos cenários existentes e prognósticos e tendências apontadas nestes estudos.

O objetivo do trabalho foi avaliar a transformação da paisagem urbana no período de cinco anos, referente à verticalização das edificações no eixo estruturador de Passo Fundo, a Avenida Brasil. Também foram avaliados os números relativos às edificações com recuos frontais e/ou laterais, bem como os usos das edificações, a fim de elaborar um diagnóstico e contribuições preliminares para os instrumentos de planejamento da cidade quanto aos gabaritos, recuos e zoneamento de usos. 


\section{Referencial teórico}

O planejamento urbano atual tem o desafio de projetar a cidade dentro de um contexto de incertezas, dada a velocidade em que as mudanças sociais têm ocorrido na sociedade hipertexto, revelando as novas relações entre privado e público, entre real e virtual, na dinâmica do trabalho e na sociabilidade dos indivíduos (Ascher, 2010). Além disso, são necessários programas de educação ambiental, de gestão de resíduos e poluentes, reutilização e renovação de fontes de energia através de um metabolismo urbano circular, possibilitado pela cidade compacta, contrapondo cidades elaboradas de maneira difusa, de metabolismo linear. 0 metabolismo linear compreende o consumo e descarte de materiais e emissões, enquanto o metabolismo circular permite a redução de desperdícios e poluentes, através do reaproveitamento (Silva \& Romero, 2013).

São recorrentes as estratégias e políticas voltadas à eficiência energética, sobretudo nas edificações, mormente isso ocorra ainda pontualmente ou de forma individualizada e em uma escala menor de complexidade. Entretanto, no contexto urbano, há a necessidade de se analisar o cenário como um todo, haja vista que o somatório dessas estratégias individuais constitui-se em imperativo para o planejamento da cidade. Entre os instrumentos de análise que contribuiriam neste processo, pode-se citar: o aprofundamento do estudo da morfologia urbana, permitindo estabelecer diretrizes em relação ao microclima e à demanda energética; a criação de modelos matemáticos com maior assertividade em relação aos fenômenos simultâneos; e os estudos voltados aos prognósticos da evolução da forma da cidade, através de modelagens, haja vista que para a elaboração das diretrizes se faz necessária a coleta de dados e de desempenho para que as estratégias correspondam ao contexto em que estão inseridas (Martins et al., 2013).

Os estudos morfológicos permitem a análise das carcaterístiscas do espaço urbano, a identificação das transformações produzidas na cidade, ao longo do tempo, tratando os aspectos físicos e as condicionantes da produção dos espaços, de maneira ampla e interdisciplinar, uma vez que o espaço é produzido pelos usuários, pelo mercado e pelas diretrizes de planejamentos anteriores, sendo assim, permitem entender o contexto atual e anterior, a fim de fornecer subídios para projetar o contexto futuro (Rego \& Meneguetti, 2011). Um dos critérios que podem ser analisados nas análises morfológicas se refere ao gabarito de altura das edificações, sendo possível identificar processos como verticalização e adensamento urbano. 0 estudo da morfologia é uma discussão recente para cidades brasileiras, podendo ser utilizado como ferramenta de planejamento, ao fornecer informações para diretrizes urbanas e adaptar o meio urbano à modificação das condições climáticas. A verticalização impacta significativamente a disponibilidade de iluminação natural, as áreas sombreadas e a visibilidade do céu, gerando aumento da absorção da radiação solar, bem como aumento da velocidade dos ventos (Silva et al., 2018).

Estudo realizados em outras regiões do Brasil permitem apontar fatores que influenciam na verticalização das áreas urbanas. Um desses estudos, em Viçosa-MG, demonstrou a demanda por habitações, comércio e infraestrutura gerada pela Universidade Federal de Viçosa (UFV), evidenciando que edificações de caráter público e educacional podem provocar novos fluxos de usuários nas áreas urbanas e, consequentemente, novas oportunidades e necessidades. Outro fator apontado foi a ocorrência de investimentos externos, simultâneos ao crescimento da universidade (Paula, 2019). Outro estudo, realizado em Macapá-AP, evidenciou as políticas de ordenamento urbano como um dos fatores preponderantes ao processo de verticalização, pela definição do gabarito das edificações. Em um período de 10 anos, a modificação dos gabaritos definiu 22 pavimentos como gabarito máximo, sendo que no período anterior este era de 12 pavimentos. Também foi observado o processo de verticalização na região amazônica, a partir de 1990, de maneira tardia em relação a outras regiões do Brasil (Batista et al., 2016).

O estudo na cidade de Torres-RS, realizado por Lima (2018), apontou o impacto da atividade turística do veraneio como fator de ocupação do espaço urbano. A atividade turística, ao criar grupos distintos de população, fixa e transitória, gerou diferentes ocupações ao longo do tempo, referentes às demandas e especificidades de cada população. A orla da praia foi o eixo indutor das primeiras edificações verticalizadas. Outro fator apontado no estudo é o papel do planejamento urbano, quanto à restrição de 
gabaritos em determinadas zonas, porém este processo gerou a verticalização em outras áreas não abrangidas na restrição. Também foi identificada a atuação de outros agentes, como o Ministério Público, no sentido de restringir aprovações de empreendimentos que extrapolassem a infraestrutura da malha urbana. Conforme Acosta (2018), questões culturais também influenciam no aceite ou não dos processos de verticalização, como na Costa Rica, onde a população historicamente mantém o vínculo à terra, seja como lavoura, seja como jardim, constituindo um padrão de horizontalidade, em contraponto ao início do processo de verticalização, que ficou condicionado a edifícios públicos como símbolos de progresso e residências de alto padrão.

A verticalização contribui para a criação de uma cidade mais compacta, sustentável e geradora de atividades sociais e culturais, através do melhor aproveitamento do solo. Porém, estudos têm levantado um questionamento, a respeito das "cidades ocas", pois, apesar da justificativa da verticalização como melhor aproveitamento do solo, alguns empreendimentos, em especial os destinados ao público de alta renda, possuem baixa densidade demográfica, apesar do impacto que a edificação gera no entorno em função de sua altura (Nakano, 2018). A verticalização gera consequências em relação ao microclima, com alteração das médias de temperatura e na velocidade dos ventos, dependendo das tipologias e recuos adotados, podendo ocasionar até o efeito de canalização, que interfere diretamente na elevação das temperaturas (Nogueira et al., 2018). 0 ruído também é outro fator a ser considerado, uma vez que as edificações verticalizadas atuam como refletores acústicos, em diversas direções, causando reverberação urbana, por consequência, requerendo cuidados quanto ao isolamento e vedações da edificação, variando conforme a largura das vias e dos recuos das edificações (Vilela et al., 2017).

A verticalização também implica questões técnico-econômicas da construção, visto que se trata de um processo que possui um limite de simultaneidade para a construção dos pavimentos, se tratando dos sistemas construtivos usuais, portanto, quanto mais alto o edifício, maior o tempo de obra por consequência (Mascaró, 2010). Entretanto, é necessário mensurar quais impactos serão gerados por este processo, a fim de preservar as condições de qualidade ambiental do espaço urbano, em especial as condições de insolação e salubridade do entorno das edificações verticalizadas (Oliveira et al., 2018). Segundo Scussel \& Sattler (2010), o processo de verticalização denota aspectos positivos e negativos pelo impacto causado no tecido urbano, da mesma maneira que o adensamento urbano, a complexidade desses fenômenos tange questões de infraestrutura, saneamento, a articulação viária e os usos que definem a qualidade dos espaços. Ascher (2010) afirma que o novo urbanismo não adota a linearidade projetual estabelecida durante o modernismo, hoje, os processos são interativos, simultâneos, com pesquisas parciais que retroalimentam o processo de planejamento. Nesse sentido, analisar a evolução do espaço urbano, baseada em critérios definidos, pode ser de grande valia para o incremento das estratégias de projeto.

Um dos parâmetros para avaliar a densidade urbana é o coeficiente de aproveitamento, que é a relação entre a área construída e a área superficial do terreno, ou seja, de construção permitida (Nakano, 2018). O plano diretor de desenvolvimento integrado de Passo Fundo, no capítulo IV, artigo 79, em seus índices urbanísticos, prevê coeficientes de aproveitamento distintos por zonas, sendo que, no trecho analisado, as quadras encontram-se nas zonas de ocupação intensiva 1 e 2 (ZOI1 e ZOI2), zona de transição (ZT), zona de ocupação extensiva (ZE), Zona de ocupação controlada 1 (ZOC1) e Zonas de uso especial (ZUE), com coeficientes de aproveitamento variando de 1,2 a 4,0, ou seja, a área máxima edificável, desconsiderando áreas de uso comum, reservatórios, subsolos e garagens até $10 \mathrm{~m}$ a partir da soleira de entrada, na ZOI1, por exemplo, será de quatro vezes a área superficial do terreno. 0 índices da ZOI1 e ZOI2, de 4,0 e 3,6, respectivamente, são os maiores índices de aproveitamento no zoneamento urbano de Passo Fundo e estão presentes em toda a extensão da Avenida Brasil, à exceção do trecho entre a rua Fidêncio Franciosi (ponte do Rio Passo Fundo) e a Rua Nilo Peçanha (viaduto da linha férrea), explicitando a indução da verticalização através do planejamento urbano e poder público.

Apesar da redução dos índices e a inclusão dos recuos, a zona central e as áreas adjacentes à Avenida Brasil ainda possuem os maiores índices construtivos no zoneamento da área urbana, bem como áreas adjacentes ao centro passaram a ter índices construtivos maiores. À guisa de comparação, o índice de 
aproveitamento na área central era de sete vezes a área dos lotes (Ferreto, 2012), hoje, na Zona de ocupação intensiva I (ZOI 1), o coeficiente de aproveitamento é de 4 vezes a área do lote. 0 plano diretor de desenvolvimento integrado (P.D.D.I.) de Passo Fundo (2006) estabelece diretrizes também para os recuos frontais e laterais de edificações. No capítulo VI, os artigos 106 a 109 tratam dos recuos frontais, laterais e de fundos, sendo os frontais obrigatórios, com no mínimo 4,00m (exceto ZOI1, até a altura de $10 \mathrm{~m}$ a partir da soleira de entrada), quando os lotes tiverem sua testada para praças e parques, o recuo frontal mínimo passa a ser de $8,00 \mathrm{~m}$ para a torre do prédio. Os recuos laterais e de fundos são calculados com fórmula pré-estabelecida, variando em função da altura da edificação, por exemplo, uma edificação com 10 pavimentos terá recuos de 3,5m a partir das divisas, considerando um pé-direito médio de $2,80 \mathrm{~m}$; quanto maior a altura da edificação, maiores serão os recuos a serem dimensionados em relação às faces laterais e de fundos. Aqui também fica evidenciado o papel dos instrumentos de planejamento na melhoria do espaço urbano, pois a exigência de recuos contribui para a iluminação natural e ventilação no meio urbano.

O plano diretor do município de Passo Fundo, no título IV, capítulo I, seção I, em seus instrumentos de controle e planejamento, também prevê que a aprovação de projetos multifamiliares verticais com área superior a $7.000,00 \mathrm{~m}^{2}$ se dê mediante a apresentação de Relatório de Impacto de Vizinhança (RIV), avaliando os impactos do empreendimento sobre o entorno, nos aspectos econômicos, paisagísticos, ambientais, sociais, do sistema viário e da infraestrutura urbana, a fim de elaborar medidas compensatórias e mitigadoras aos efeitos negativos que o empreendimento possa gerar. Cabe salientar que o plano diretor de Passo Fundo está em processo de revisão, assim, estes índices, o zoneamento, bem como os instrumentos de controle podem ser modificados em breve.

\section{Caracterização da área de estudo}

Passo Fundo, localizada no norte do Rio Grande do Sul, possui 203.275.000 habitantes, segundo estimativa realizada em 2019 pelo IBGE (2018), um acréscimo de 9,9\% em relação à população apontada no censo de 2010, com 184.826,000 habitantes (sendo 97,45\% de população urbana), e 235,92 hab/km² de densidade, sendo o $12^{\circ}$ município mais populoso do Rio Grande do Sul. Esta densidade está relacionada em grande parte à perceptível verticalização da cidade, em especial ao longo da Avenida Brasil, tratando-se de um processo histórico, pois a Avenida é o eixo estruturador de urbanização da cidade, que fora caminho dos tropeiros e, desde a década de 1970, passa por um processo gradual de verticalização da área central, devido à oferta de serviços e comércio, característica da Avenida (Gosch, 2002).

A densidade urbana de Passo Fundo também decorre da condição de polo médico e educacional, aumentando a demanda de apartamentos, escritórios e consultórios, salas comerciais e outras atividades concentradas ao longo da Avenida. Outro fator a ser considerado, segundo Ferreto (2012), é a influência da mecanização na agricultura, que impulsionou gradativamente o êxodo rural, porém não significando perda de importância da atividade rural, mas o estabelecimento de uma nova relação entre meio urbano e meio rural. Ainda conforme Ferreto (2012), a população urbana de Passo Fundo superou a rural na década de 1960, com 97,45\% dos habitantes vivendo na área urbana no ano de 2010.

A configuração da malha urbana parte da Avenida Brasil como eixo estruturador da cidade, utilizada como rota comercial e acampamento pelos tropeiros, de maneira gradual, passou de local de passagem para núcleo urbano, a partir de 1850, com a exploração da erva-mate pelos primeiros produtores a se fixarem no local. Em 1857, Passo Fundo constituiu-se como município, logo em seguida recebendo imigrantes italianos e alemães, que contribuíram de maneira significativa para o aumento populacional e incremento das atividades comerciais (Gosch, 2002). Ao longo desse processo, a rota dos tropeiros transformou-se em rua do comércio, característica que permanece até hoje, novos eixos de desenvolvimento como a linha férrea desenvolveram-se a partir da Avenida Brasil, que reafirmaram sua importância como elemento articulador das atividades urbanas (Gelpi et al., 2005). 
O primeiro plano diretor de Passo Fundo foi aprovado em 1953, delimitando zonas residenciais e comerciais, porém sem estabelecer índices urbanísticos (Gosch, 2002). Segundo Ferreto (2012), o plano tratava-se de um registro do período em relação ao ano de 1922, quando foi implantado o plano de saneamento pelo sanitarista Saturnino de Brito, visto que a modificação da paisagem se deu pela criação de loteamentos periféricos pela iniciativa privada, simultaneamente ao processo de verticalização iniciado no centro, estabelecendo uma lógica de produção do espaço urbano. A criação da Universidade de Passo Fundo, em 1968, e a implantação de tradicionais escolas na cidade agregaram os serviços educacionais às atividades desenvolvidas na avenida e seu entorno, seguida da implantação de bancos, hotéis e as primeiras edificações multifamiliares. Os serviços de saúde, através dos hospitais e consultórios privados, também tiveram imporante papel na configuração da cidade como polo de comércio, saúde e educação, evidenciando ainda a atuação da iniciativa privada neste processo. 0 exôdo rural, a partir de 1940, também contribuiu para o aumento populacional. A Figura 1 apresenta vistas aéreas da Avenida Brasil nos anos de 1966 e 1970, respectivamente:
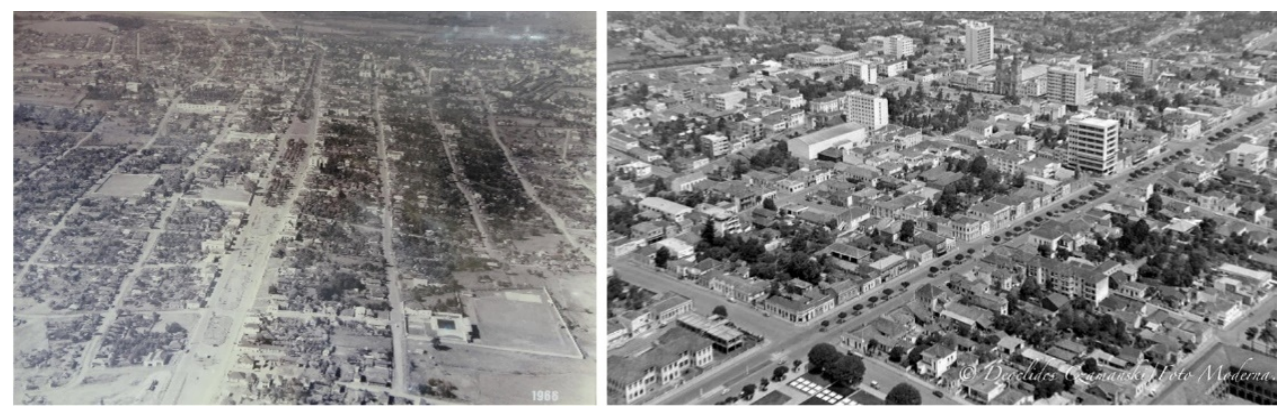

Figura 1 - Da esquerda para a direita, vista aérea da Avenida Brasil no ano de 1966 e vista aérea da Avenida Brasil no ano de 1970. Fonte: Czamanski (1966) e Czamanski (1970).

Em 1960, devido às demandas por habitação criadas pelo êxodo rural, o setor imobiliário passou a produzir loteamentos fora da área central, periféricos, com foco na população de baixa renda, muitas vezes com pouca infraestrutura, dispersando as áreas urbanas. Programas habitacionais do governo estadual promoveram habitações de interesse social (Ferreto, 2012). Ainda conforme Ferreto (2012), a verticalização se intensifica na década de 1970, provocando o aumento do valor dos imóveis e o adensamento urbano, concentrando edifícios de apartamentos de classes média e alta, que permanecem ocupando a área central, sendo esse processo também a construção de uma imagem de progresso através das edificações verticais. Segundo Gosch (2002), em 1979, a revisão do plano diretor aliada à evolução das tecnologias construtivas e a especulação imobiliária contribuíram com o processo de verticalização da cidade, uma vez que incentivava o adensamento da área central, a definição de usos e zonas, induzindo a potencialização da Avenida como centro econômico e social, com edificios multifamiliares e galerias comerciais, alterando de maneira significativa a paisagem urbana da cidade, evidenciando a conjuntura entre interesses públicos e privados na elaboração das políticas urbanas e moldagem de uma imagem progressista do centro urbano.

Nas décadas seguintes, o processo de verticalização se irradia a partir da Avenida Brasil, com o crescimento populacional e a implantação de shopping centers, reforçando o caráter comercial da área central e impulsionando a demanda por habitação (Gelpi et al., 2005). Em 1984 e 1988, são modificadas diretrizes do plano diretor, que seria revisado novamente em 2006, já nos moldes do Plano atual, cabendo salientar a inclusão de diretrizes como a exigência de recuos frontais obrigatórios e recuos laterais e de fundos, calculados em função da altura das edificações, visando à melhoria do espaço urbano edificiado (Gosch, 2002). 0 processo de verticalização na Avenida, em especial na zona central, se deu através da substituição das tipologias existentes, residenciais ou comerciais de até dois pavimentos, pelas edificações mistas e múltiplos pavimentos, porém mantendo a característica de uso misto, como comércio no pavimento térreo e apartamento nos pavimentos superiores (Ferreto, 2012). 
Na década de 1990, shopping centers, ainda que com tipologia de galeria comercial, constituem-se empreendimentos que incrementaram de forma significativa o comércio e a oferta de serviços na área central. A implantação do Shopping Center Bella Città impacta a paisagem pelo porte do empreendimento e constitui-se marco na paisagem (Ferreto, 2012). A Figura 2 demonstra o mapa elaborado por Ferreto (2012) sobre a ocupação do espaço urbano ao longo do tempo:

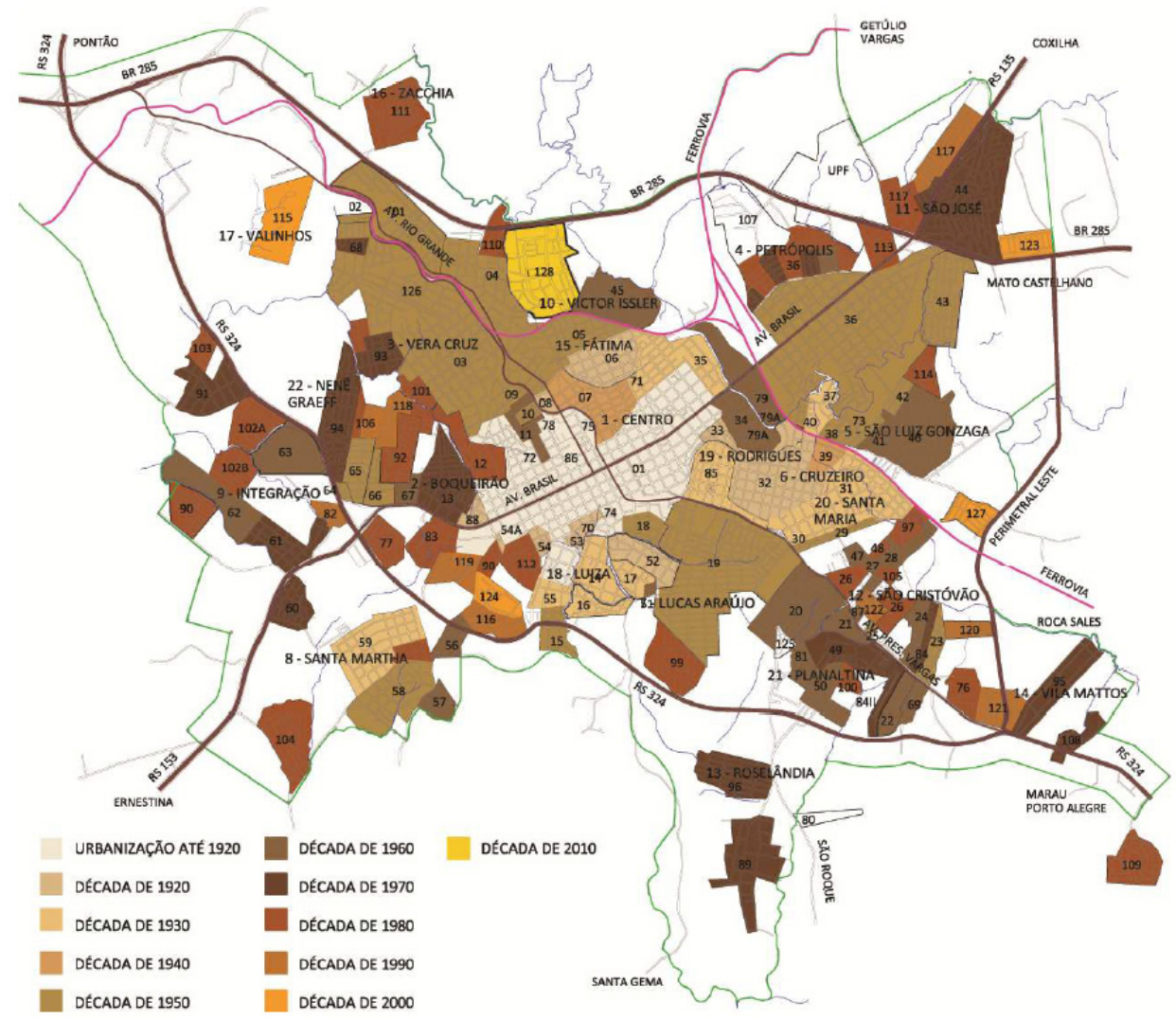

Figura 2 - Ocupação da área urbana de Passo Fundo até 2010. Fonte: Ferreto (2012).

A tendência de verticalização segue nos anos subsequentes, com a dispersão para outras centralidades, impulsionadas também pelo crescimento da estrutura dos hospitais e a constituição do polo médico. 0 processo iniciado na década de 1970 rompe com a paisagem estabelecida até então, trazendo uma nova escala ao espaço urbano, impactando a morfologia de Passo Fundo (Gosch, 2002). 0 estudo de Ferreto (2012) também apontou tendências de ocupação do território, entre elas a dinâmica da construções de edifícios na área central, a implantação de condomínios de alto padrão em áreas periféricas como vetor de dispersão urbana e, como vetores de expansão urbana, a implantação de novos loteamentos e o plano muncipal visando a ocupação na faixa sudoeste, incluindo os bairros Santa Marta e Integração. A Avenida Brasil, como eixo estruturador, teve suas primeiras ocupações estabelecidas até 1920, posterior ao primeiro núcleo iniciado na atual praça Tamandaré. 0 bairro Petrópolis, que inclui um dos trechos da Avenida, passou a ser ocupado a partir da década de 1950 e o trecho do bairro Boqueirão a partir de 1970 .

O processo de revisão do Plano Diretor de Passo Fundo está em andamento, constituído por quatro etapas. A primeira trata da metodologia participativa e do plano de comunicação e mobilização. A segunda etapa coloca uma análise técnica e comunitária, o diagnóstico participativo, de maneira a sistematizar o entendimento da ocupação do território bem como suas tendências de uso. A etapa seguinte é constituída pela concepção do plano, com oficinas de proposições, seminários e a validação dos estudos de concepção. A quarta e última etapa, ainda não iniciada, refere-se à elaboração do projeto de Lei e posterior conferência e consulta pública (Passo Fundo, 2020). 


\section{Método}

A análise compreendeu o trecho da Avenida Brasil, entre a BR 285 e RS 135, abrangendo os bairros Centro, Petrópolis e Boqueirão, com aproximadamente 7,62 quilômetros e 96 quadras. 0 primeiro levantamento realizado neste estudo ocorreu no período de maio a julho de 2013, enquanto o segundo levantamento foi de junho a julho de 2018. Foi realizado in loco, com registro fotográfico das edificações, quadra por quadra, registrando os dados relativos à altura, recuos e usos das edificações.

Os dados coletados nos levantamentos foram tabelados, quantificando o gabarito de altura e número de edificações quadra a quadra, nos dois períodos, para compreensão das modificações da paisagem urbana ao longo da Avenida Brasil. No referente à verticalização, as edificações foram classificadas conforme o gabarito de altura, nos seguintes grupos: 1 a 2 pavimentos; 3 a 6 pavimentos; 7 a 12 pavimentos e edificações maiores que 13 pavimentos. Em relação aos recuos, foi avaliada a presença e ausência de recuos frontais e/ou laterais nas edificações. Também foram coletados dados referentes aos usos, classificando as edificações como residenciais, comerciais, institucionais ou de uso misto. Os resultados foram comparados e então analisados os fatores que implicam o processo de verticalização, assim como o benefício da utilização de recuos na qualidade do espaço urbano. A Figura 3 indica o trecho analisado e sua inserção na área urbana e a Figura 4 ilustra a área central de Passo Fundo:

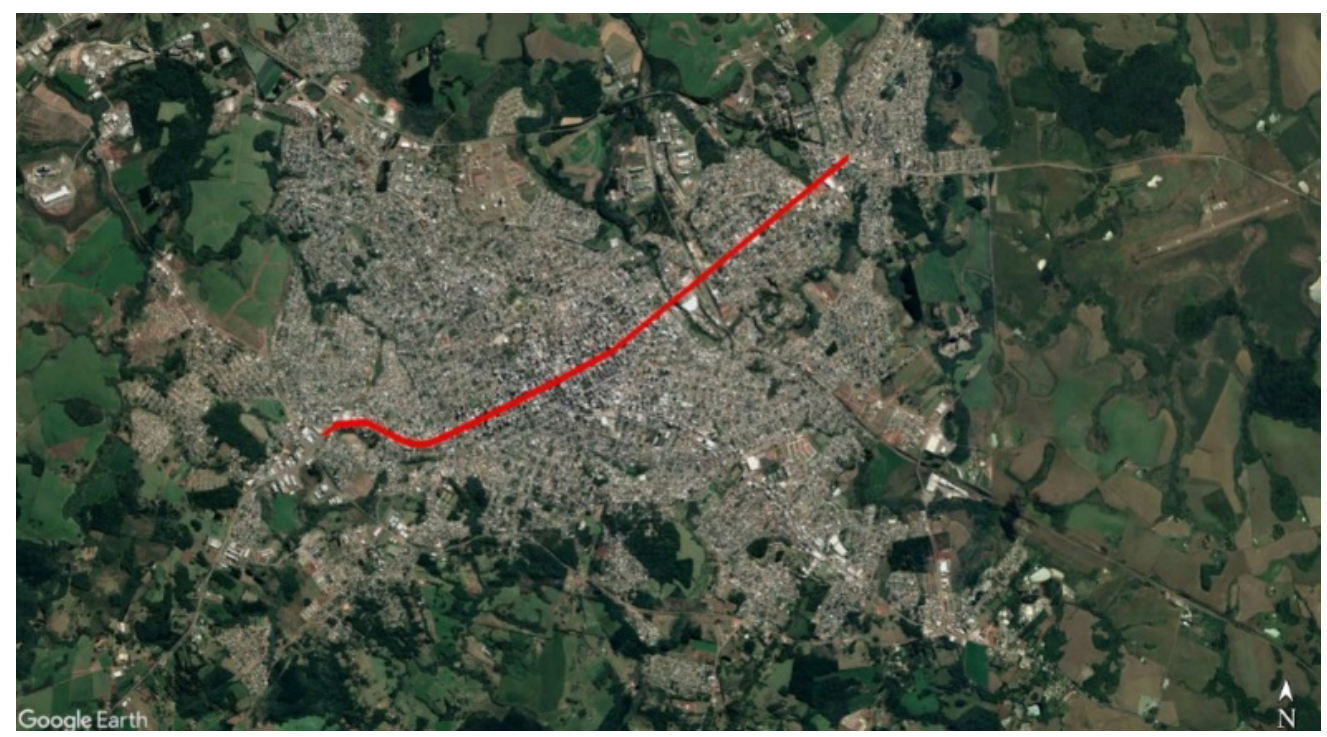

Figura 3 - Mapa identificando o trecho analisado dentro da área urbana de Passo Fundo. Fonte: Google Earth (GOOGLE, 2018), adaptado pelos autores.

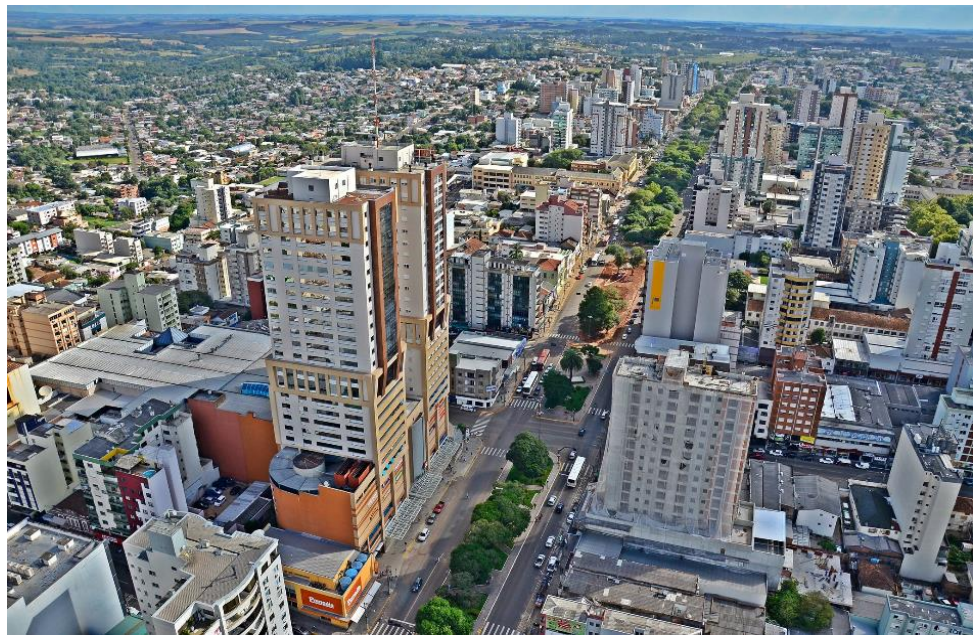

Figura 4 - Vista aérea da Avenida Brasil no bairro Centro. Fonte: Borgman (2019). 


\section{Resultados e discussões}

A análise dos gabaritos de altura demonstrou a continuidade da tendência de verticalização da Avenida Brasil. Houve crescimento dos índices em todos os gabaritos de altura apontados, destacando o crescimento das edificações maiores que 13 pavimentos, passando de 9 para 16 edifícios, um crescimento de $78 \%$ em relação ao apontado no levantamento de 2013. No levantamento in loco, também foi perceptível a implantação de novos empreendimentos de mesma tipologia nas ruas adjacentes à Avenida Brasil, como as ruas Moron e Paissandu, acentuando a noção de espaço verticalizado. As edificações de 1-2 pavimentos ainda predominam no número total de edificações, em especial nos bairros Boqueirão e Petrópolis, com predomínio de edificações comerciais e de urbanização tardia em relação ao Centro, que continua sendo o bairro mais adensado. 0 crescimento só não é mais expressivo, devido à criação de novas centralidades, que têm atraído novos empreendimentos, por exemplo, o bairro Vergueiro e a Vila Rodrigues, distanciados da Avenida e que vêm recebendo a implantação de edificações exclusivamente residenciais, de alto padrão e verticalizadas, em média de 15 a 30 pavimentos. Outra centralidade está localizada na Avenida Presidente Vargas, na qual foi implantado um shopping center, atraindo empreendimentos verticais residenciais para o entorno. 0 Gráfico 1 demonstra o comparativo do total de edificações, classificadas quanto ao gabarito de altura:
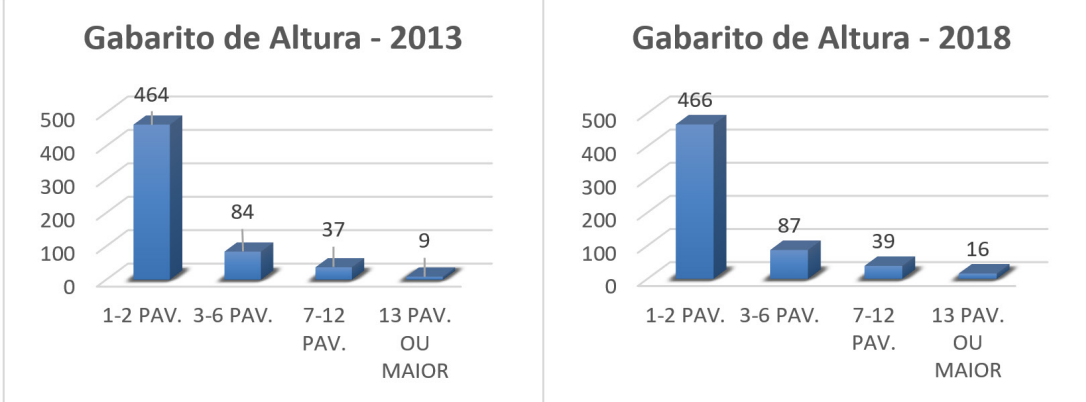

Gráfico 1 - Resultado dos levantamentos de 2013 e 2018, referente ao quantitativo de edificações conforme os gabaritos de altura. Fonte: Elaborado pelos autores (2018).

O bairro Cidade Nova, no lado oposto da Cidade, também tem recebido empreendimentos verticalizados, residenciais e comerciais, gradualmente se consolidando como uma nova centralidade. Cabe salientar também que os Hospitais (São Vicente, Pronto Clínica e Hospital da Cidade) também atuam como polos de verticalização, atraindo empreendimentos residenciais, comerciais e de uso misto em seu entorno, também verticalizados. 0 edifício mais alto na Avenida Brasil é o Bella Città Shopping Center, com 25 pavimentos acima do solo. A Figura 5 ilustra a tipologia de edificações verticais localizadas ao longo da Avenida:
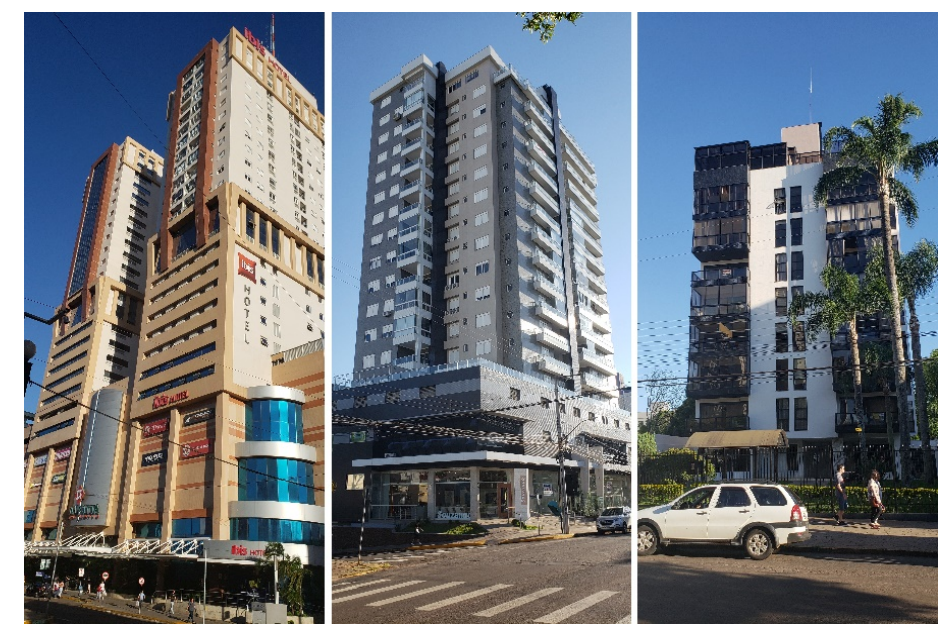

Figura 5 - Da esquerda para a direita: Bella Città Shopping Center com 25 pavimentos, edifício de uso misto com 18 pavimentos e edifício residencial com 9 pavimentos. Fonte: Os autores (2018). 
Os valores e as dimensões dos terrenos na área central também podem ser apontados como fatores influentes na verticalização, uma vez que incorporadores utilizam o índice construtivo máximo disponível, para obter o maior retorno possível sobre seus empreendimentos. 0 aumento da densidade se dá através da utilização do maior número possível de unidades permitidas aos empreendimentos, consequência também da redução da área das unidades, tendência nacional de mercado, em especial para os apartamentos tipo "studio", voltados a novos públicos e demandas do mercado. Outro fator percebido em relação às tipologias é que a Avenida não tem recebido empreendimentos de alto padrão, exclusivamente residenciais e com poucas unidades, sendo estes empreendimentos alocados em bairros residenciais, como as vilas Rodrigues e Vergueiro, ainda próximos ao centro mas com pelo menos 7 quadras de distância em relação à Avenida, que também estão passando por processo de verticalização. As tecnologias construtivas também têm influenciado a velocidade em que as obras são concluídas, fazendo com que a paisagem seja modificada de maneira mais acelerada.

O levantamento de 2013 apontava 594 edificações ao longo do trecho analisado, em 2018, são 608, um crescimento de 2,35\%, cabendo salientar a demolição de edificações térreas comerciais ou residenciais, gerando espaço aos novos empreendimentos multifamiliares, de uso misto comercial e residencial, dando perenidade à vocação comercial da Avenida e caracterizando a substituição de tipologias. De certa forma, a Avenida passa a retomar características residenciais propostas neste momento pelo uso misto, além dos benefícios relacionados à disponibilidade de serviços, transporte público e acesso à ciclovia. 0 número só não é mais expressivo devido à criação das novas centralidades anteriormente citadas. Em parte, duas ou mais edificações acabam sendo demolidas para viabilizar os empreendimentos em função da exigência de vagas de estacionamento privativo.

Todavia, ainda existem prédios remanescentes de décadas anteriores ao processo de verticalização, em especial os que constituem patrimônio histórico do município, evidenciando os contrastes da paisagem na área central, conforme as Figuras 6 e 7:

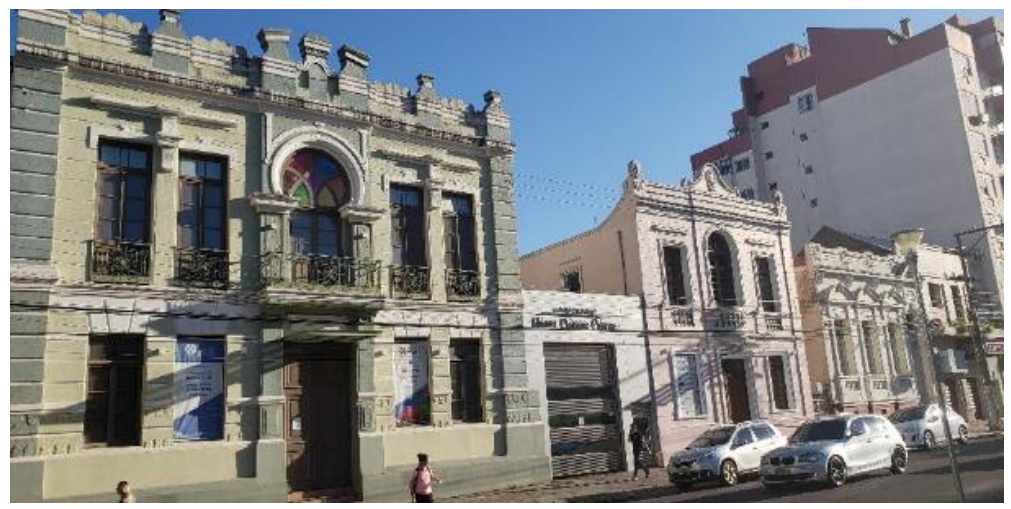

Figura 6 - Da esquerda para a direita: Museu de Artes Visuais Ruth Schneider, Teatro Municipal Múcio de Castro e Academia Passo-Fundense de Letras. Fonte: Os autores (2018).

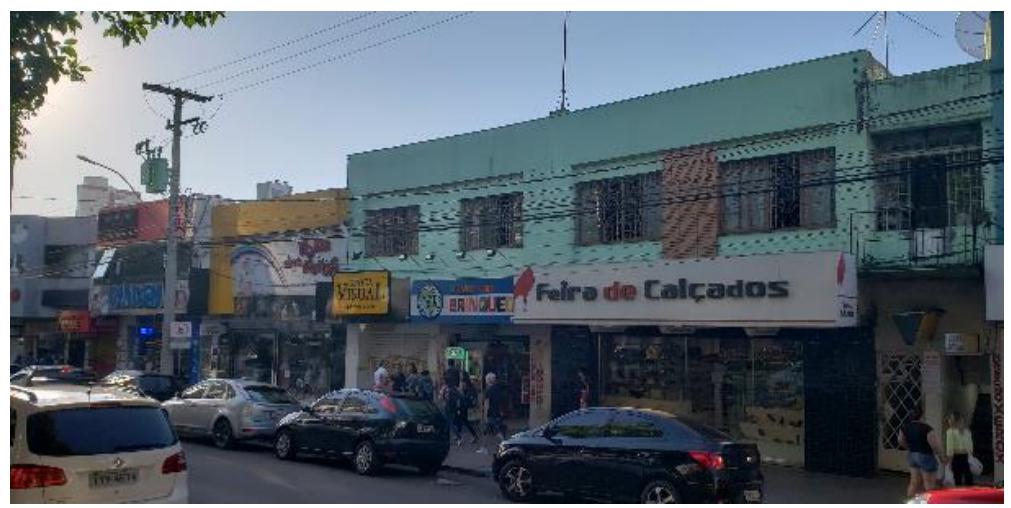

Figura 7 - Edificações comerciais de até dois pavimentos na área central. Fonte: Os autores (2018). 
Referente às edificações com recuos, nota-se crescimento das edificações com recuos, cerca de $17 \%$ em relação ao primeiro levantamento, devido à exigência de recuos frontais e laterais obrigatórios pelo Plano Diretor de Desenvolvimento Integrado. Esses recuos são proporcionais à altura das edificações, sendo o recuo frontal obrigatório de 4 metros, exigidos para novas construções. 0 Gráfico 2 demonstra o comparativo da quantidade de edificações com ou sem recuos:

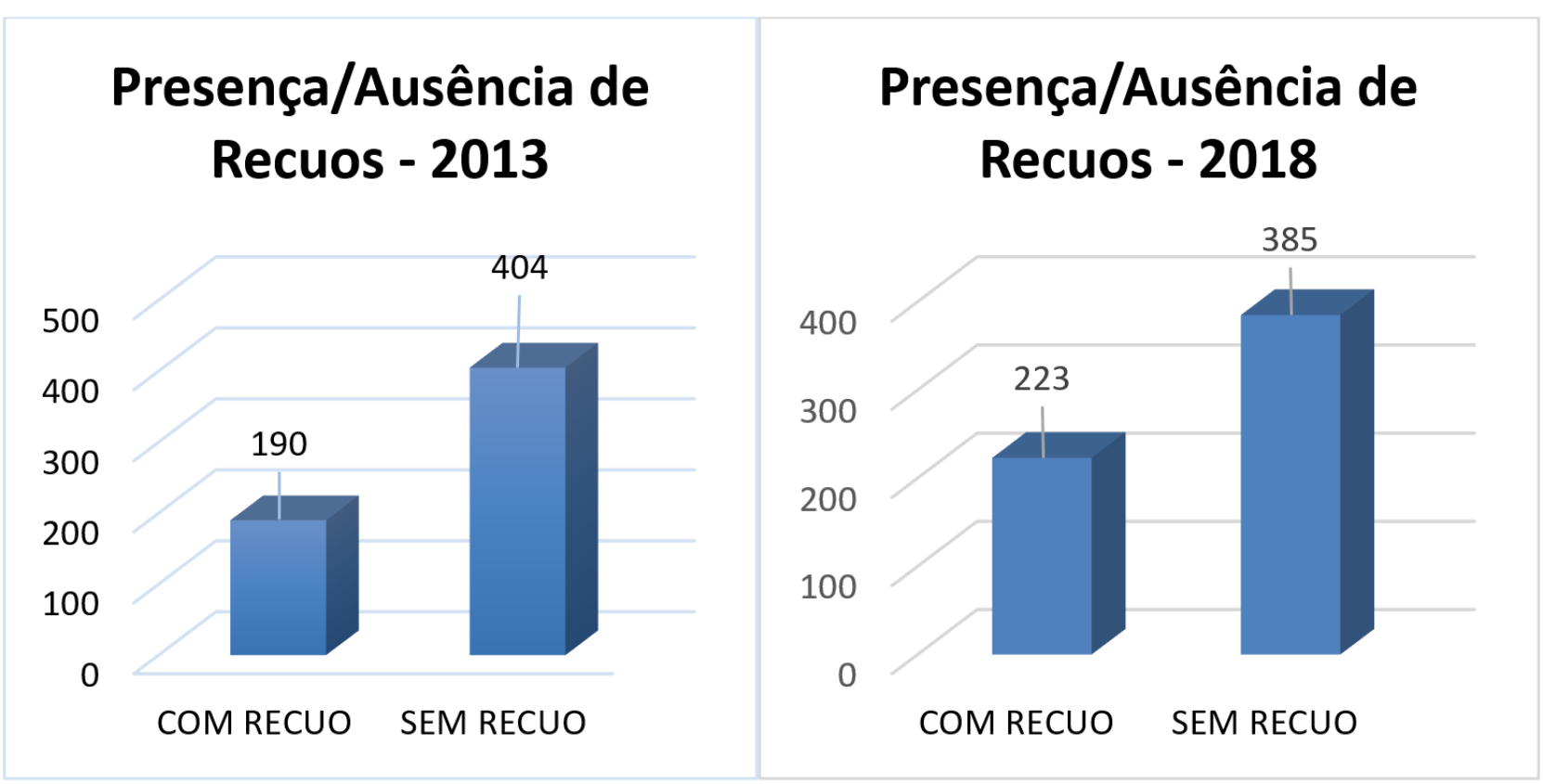

Gráfico 2 - Resultado dos levantamentos de 2013 e 2018, referente aos recuos. Fonte: Elaborado pelos autores (2018).

Nas edificações verticalizadas, os recuos laterais e de fundos permitem a ventilação e iluminação natural, além de reduzirem as condições para a criação de "corredores de vento", existentes em outras áreas verticalizadas da cidade e com caixa de rua menor. Cabe salientar que a Avenida varia de 2 a 3 faixas de rolamento somadas aos estacionamentos, além dos largos canteiros centrais, que propiciam qualidade aos espaços ao longo de sua extensão. Mesmo em edificações térreas, em geral pavilhões comerciais, outra tipologia recorrente na Avenida, o uso de recuos frontais obrigatórios tem se mostrado benéfico, pela criação de vagas de estacionamento, áreas permeáveis e ampliação do cone visual do pedestre, conforme Figura 8:
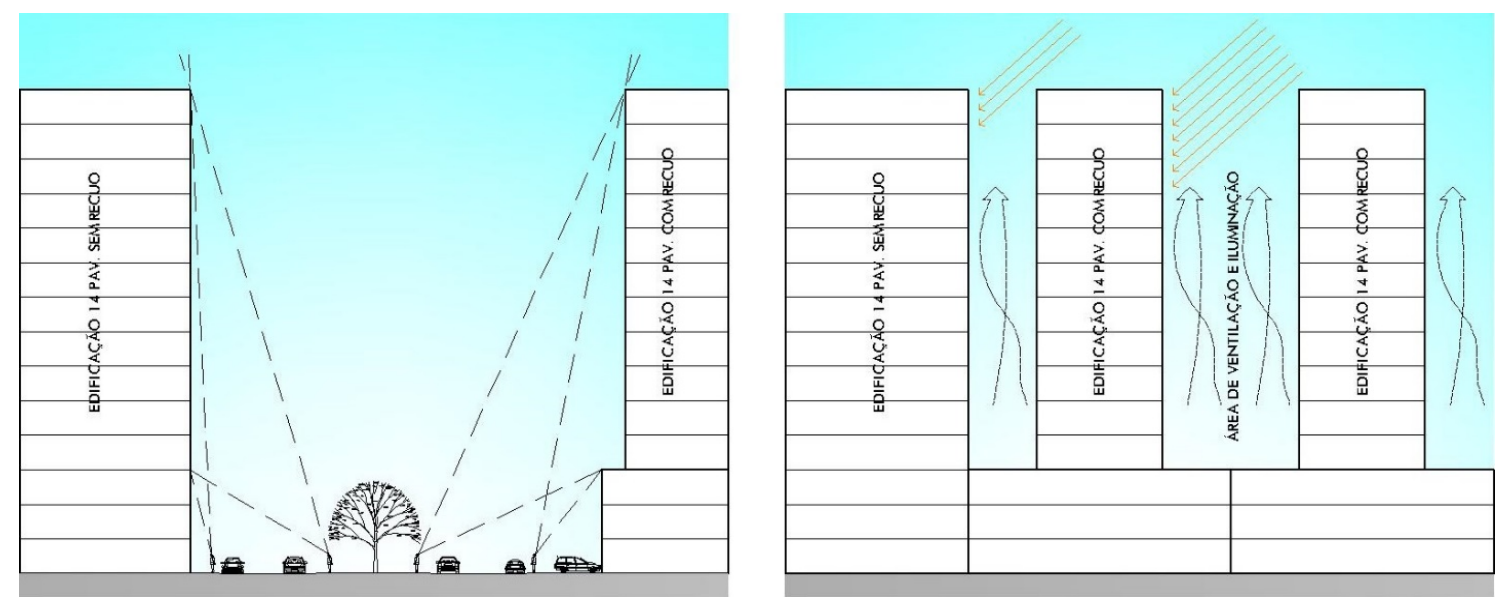

Figura 8 - Croqui comparativo do cone visual de pedestres em relação às edificações com e sem recuos e croqui referente a afastamentos laterais. Fonte: Os autores (2018). 
No tocante aos usos, o levantamento demonstrou o crescimento dos usos comercial e misto, uma tendência histórica da Avenida Brasil, através da substituição de tipologias. Nos bairros Boqueirão e Petrópolis, predominam as edificações comerciais, em especial pavilhões comerciais, lojas, supermercados e postos de combustíveis. Referente aos usos das edificações, o uso exclusivamente residencial diminuiu 20,96\%; o uso comercial cresceu 3,36\%; o uso misto cresceu $7,86 \%$; e o uso institucional cresceu 7,4\%. Percebe-se assim o claro crescimento das edificações de uso misto. 0 Gráfico 3 demonstra o comparativo da quantidade de edificações conforme os usos:

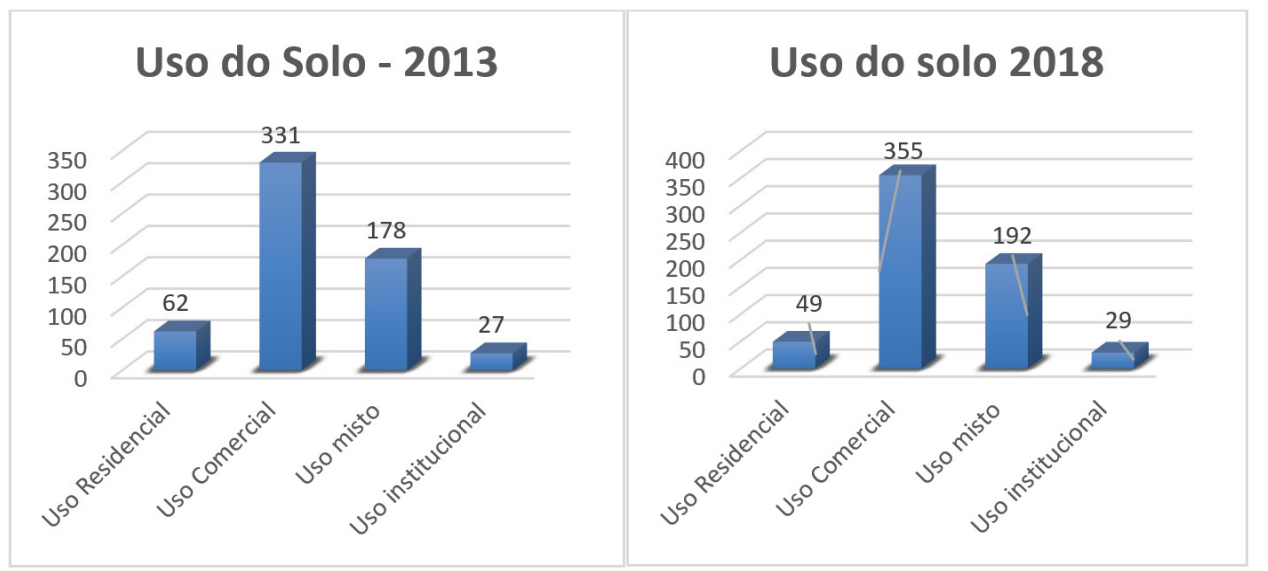

Gráfico 3 - Resultado dos levantamentos de 2013 e 2018, referente aos usos. Fonte: Elaborado pelos autores (2018).

No contexto da paisagem urbana, percebe-se a importância de equipamentos urbanos e edificações comerciais na promoção do adensamento e verticalização. 0 estudo realizado por Paula (2019), em Viçosa-MG, identificou a influência da Universidade Federal de Viçosa (UFV) e sua expansão na modificação da paisagem, ao afetar a zona central da cidade pela demanda de habitações, infraestrutura e comércio para estudantes, professores e demais empregos gerados pela instituição pública. Na década 1960, a Universidade de Passo Fundo, através de seu primeiro Campus, bem como os colégios privados com internatos, exerceram influência semelhante ao criarem novas vagas de emprego e estudo, além de atraírem população transitória, vinda de munícipios próximos a Passo Fundo. Outro ponto em comum com a verticalização ocorrida em Viçosa, em um período mais recente, é a presença de investidores externos, acompanhando o fluxo do mercado imobiliário local e as novas oportunidades de negócios criadas anualmente, que ocorre de maneira simultânea à expansão de institutos educacionais.

0 estudo realizado por Batista et al. (2016) em Macapá-AP, aponta a legislação como um dos fatores que impactaram o processo de verticalização, através da definição de gabaritos máximos. Em 2004, o máximo permitido variava entre 22 e 33m ( 8 a 12 pavimentos) e, em 2014, o gabarito máximo era de 76m (22 pavimentos). Ao traçar um comparativo com Passo Fundo, no aspecto da legislação, o Plano Diretor vem reduzindo índices construtivos em determinadas áreas e a inclusão de afastamentos laterais e de fundos, a partir dos 10 metros de altura, na área central, juntamente com as taxas de ocupação (em média $60 \%$ para as torres residenciais e comerciais), no sentido de regular a verticalização. Atualmente, há edifícios que atingem 30 pavimentos de altura. Outro ponto a ser delineado entre os estudos é relativo ao período, enquanto Macapá e a região amazônica têm seu processo de verticalização intensificado a partir da década de 1990, Passo Fundo apresenta seu processo contínuo desde a década de 1980.

Outro estudo, realizado por Lima (2018) em Torres-RS, demonstra o impacto da atividade turística na consolidação do espaço urbano. A prática do veraneio conformou a paisagem urbana de Torres através de grupos de população distintos, de moradores com residência fixa e os moradores temporários, tendo a orla como eixo estruturador das primeiras edificações verticalizadas. 0 estudo também evidenciou a influência do planejamento urbano, uma vez que o plano diretor, ao restringir edificações com mais de dez pavimentos em determinada área, induziu a verticalização em outras zonas não afetadas pela redução, bem como intervenções realizadas por outros agentes públicos, no sentido de impedir a 
aprovação de empreendimentos de forma deliberada, sem que houvesse infraestrutura básica para sua implantação. Em Passo Fundo, não é evidente a característica do turismo como fator preponderante na construção do espaço, apesar da constituição do parque da Roselândia e outras áreas delimitadas como de recreação e turismo. Entretanto, é possível traçar um paralelo entre as duas cidades, no que tange à população transitória, pois, além da população residente apontada no censo, Passo Fundo possui movimentos pendulares de população, sendo o principal deles o fluxo de estudantes para as instituições de ensino superior, que fixam residência durante o período letivo e, em parte, voltam à cidade de origem nos períodos de férias, gerando assim uma grande demanda por imóveis para locação, em especial na área central, servida por redes de transporte coletivo e próxima a algumas das instituições de ensino superior e, também, de colégios públicos e privados.

No atinente aos vetores de expansão e adensamento do espaço urbano, a partir do estudo e a comparação com estudos semelhantes, é perceptível o conjunto de fatores que impactam a construção da paisagem, dentre os quais cabe destacar: a produção do setor imobiliário, ao explorar comercialmente as áreas centrais; a legislação e instrumentos de planejamento urbano, que interferem diretamente não só nos usos, mas nas possibilidades de adensamento, permeabilidade e infraestrutura do espaço urbano; por fim, equipamentos urbanos que impactam a criação de novos públicos, demanda por transportes e serviços, sendo em sua maioria hospitais, universidades e shopping centers.

A partir dos resultados obtidos e de estudos semelhantes, é possível identificar claramente a atuação do poder público, do interesse privado e do interesse coletivo na construção da paisagem urbana. A elaboração dos planos diretores e instrumentos de planejamento de forma participativa estabelece um espaço para que as diferentes demandas destes produtores do espaço urbano se conectem, sendo assim, os estudos dos impactos positivos e negativos das transformações ocorridas em cada período podem subsidiar a escolha de melhores práticas nesse processo, visando ao desenvolvimento sustentável das cidades, com a participação de todos os setores envolvidos na produção do espaço urbano.

\section{Considerações finais}

Em um período de 5 anos, a paisagem da Avenida Brasil continuou em plena transformação, com empreendimentos novos, modificando o espaço construído, em face das novas demandas dos usuários e do mercado, mesmo em um cenário econômico desfavorável em nível nacional. Passo Fundo, fortalecendo cada vez mais o polo comercial, médico e educacional, atrai investidores pelas oportunidades oferecidas pelo mercado local, dessa forma, são constantes as transformações do espaço urbano em um contexto de desenvolvimento.

O estudo constatou a tendência histórica de verticalização da Avenida Brasil, desde rota das tropas, rua do comércio até os dias de hoje, como eixo estruturador e indutor de desenvolvimento. 0 adensamento da área central possui aspectos positivos, sobretudo em relação à mobilidade urbana, com empreendimentos de uso misto, com moradia e trabalho ocupando a mesma superfície, contribuindo para a não utilização de automóveis, dadas as proximidades à oferta de comércio e serviços, ao transporte urbano e à ciclovia, implantada durante o período analisado. A ciclovia também agregou valor paisagístico à área central, uma vez que os canteiros centrais da Avenida estão sendo revitalizados e sendo apropriados pela população. As diretrizes do Plano Diretor de Desenvolvimento Integrado, através de instrumentos como os recuos frontais e laterais, permitem a qualificação do espaço urbano, melhoria do espaço e do cone visual para os pedestres, criação de vagas de estacionamento para as áreas comercias, melhor iluminação e ventilação entre as edificações, além da questão da acústica urbana. 0 plano encontra-se em revisão, sendo que as diretrizes existentes para melhoria do espaço urbano devem contemplar estratégias relativas à mobilidade urbana, à melhoria da ambiência, como também incentivos para recuos além do mínimo exigido. A Cota ideal por dormitório, que permite a regulação do adensamento urbano, também deve estar interligada à disponibilidade de infraestrutura, principalmente 
a de saneamento. Paralelamente a essas medidas, o código de obras também pode incluir diretrizes visando à sustentabilidade das edificações.

Os vetores de expansão e adensamento urbanos em Passo Fundo podem ser identificados claramente em épocas distintas, apresentando como marcos fenomenais o êxodo rural e a permanência de camadas médias e altas da sociedade na área central a partir de 1960, aliadas à tecnologia construtiva, os quais incentivaram a produção imobiliária a irradiar a partir da área central. Quanto aos equipamentos urbanos, destacam-se a Universidade de Passo Fundo e os colégios com internato, na década de 1970, e os hospitais. Posteriormente, os shopping centers e galerias comerciais também tiveram influência no adensamento do entorno da Avenida Brasil. A legislação também teve impacto através da permissividade dos índices construtivos, muito embora tenha havido redução dessa permissividade entre os planos diretores.

A análise da paisagem urbana se coloca como uma ferramenta valorosa para estabelecer diretrizes para a construção de um espaço urbano acessível e sustentável, em face das novas demandas que surgirão futuramente. 0 diagnóstico da evolução do espaço urbano permitirá ao poder público traçar estratégias mais assertivas para os instrumentos de planejamento, induzindo o ordenamento sustentável das cidades.

\section{Agradecimentos}

Agradecemos à Fundação Universidade de Passo Fundo pela bolsa de mestrado.

\section{Referências}

Acosta, S. (2018). Análise teórica para desvendar o lento aceite da recente verticalização residencial em San José, Costa Rica. Urbe. Revista Brasileira de Gestão Urbana, 10(3), 677-694. http://dx.doi.org/10.1590/21753369.010.003.ao14.

Ascher, F. (2010). Os novos princípios do urbanismo. São Paulo: Romano Guerra.

Barros, M. F. D., \& Carriço, J. M. (2019). Esvaziamento e transformação morfológica da área central de Santos/SP: gênese e perspectivas. urbe. Revista Brasileira de Gestão Urbana, 11, e20180100. http://dx.doi.org/10.1590/21753369.011.e20180100.

Batista, A. J., Brito, D. M. C., \& Pantoja, G. M. T. (2016). O processo de verticalização urbana em Macapá/AP. GeoAmazônia, 4(8), 46-63.

Borgman, A. (2019). Foto aérea de Passo Fundo em 2019. Recuperado em 28 de setembro de 2020, de https://guaiba.com.br/wp-content/uploads/2020/04/passo-fundo-1.jpg

Czamanski, D. (1966). Foto aérea de Passo Fundo em 1966. Recuperado em 11 de agosto de 2018, de https://scontent.fpfb2-1.fna.fbcdn.net/v/t31.0-

8/13320410_1216065518411979_2450212141271992822_o.jpg?_nc_cat=108\&_nc_sid=9267fe\&_nc_eui2=AeHBe Z7P7Lw7mHMdRAreYPHngrENLUw-hQKCsQ0tTD6FAiGtez7o5jht3pWUqw9-

yiK4zsT1D6qpoQstA9R39EIr\&_nc_ohc=2JXP910MFSsAX_ppXDU\&_nc_ht=scontent.fpfb2-

1.fna\&oh=f26e26622a637fa0ae9137f040bb5435\&oe=5F96A2E1

Czamanski, D. (1970). Foto aérea de Passo Fundo em 1970. Recuperado em 11 de agosto de 2018, de https://scontent.fpfb2-1.fna.fbcdn.net/v/t31.0-

8/1980004_1090637444288121_948478054196313640_o.jpg?_nc_cat=103\&_nc_sid=9267fe\&_nc_eui2=AeFHuol V2z_Q58mW_tB2101sU8dYyRS9hZJTx1jJFL2FkgWMaH3B_dMpxGK520SGeiAklzbvkHHwLgdmBG4zy5zN\&_nc_ohc =LHpIi5Ll_bYAX_pZzun\&_nc_ht=scontent.fpfb2-1.fna\&oh=a91f4ce2cf6d2b709a498416005dcd0f\&oe=5F9773F2

Ferreto, D. (2012). Passo Fundo: estruturação urbana de uma cidade média gaúcha (Dissertação de mestrado). Faculdade de Arquitetura e Urbanismo, Universidade de São Paulo, São Paulo. 
Gelpi, A., Gosch, L. R. M., \& Kalil, R. M. L. (2005). Avenida Brasil: do comércio tropeiro ao shopping center. In Anais do I Colóquio Internacional sobre o Comércio e Cidade. São Paulo: USP.

GOOGLE (2018). Google Earth Pro versão 7.3.3.7786. USA: Google Inc..

Gosch, L. R. M. (2002). Passo Fundo: de Saturnino de Brito ao Mercosul (Dissertação de mestrado). Programa de Pós-graduação em Urbanismo, Universidade Federal do Rio de Janeiro, Rio de Janeiro.

Instituto Brasileiro de Geografia e Estatística - IBGE. (2018). Panoroma do municipio de Passo Fundo. Recuperado em 20 de agosto de 2018, de https://cidades.ibge.gov.br/brasil/rs/passo-fundo/panorama

Jourda, F. H. (2013). Pequeno manual do projeto sustentável. São Paulo: Gustavo Gilli.

Keeler, M., \& Burke, B. (2010). Fundamentos de projeto de edificações sustentáveis. Porto Alegre: Bookman.

Leonelli, G. C. V., \& Campos, E. F. R. (2018). Leis expansivas para a expansão urbana: campinas sem limites. Urbe. Revista Brasileira de Gestão Urbana, 10(Supl. 1), 36-48. http://dx.doi.org/10.1590/2175-3369.010.supl1.ao03.

Lima, C. F. V. (2018). A legislação urbana e as alturas construídas: a verticalização no município de Torres/RS de 1962-2017 (Dissertação de mestrado). Programa de Pós-graduação em Planejamento Urbano e Regional, Universidade Federal do Rio Grande do Sul, Porto Alegre.

Martins, T. A. L., Bonhomme, M., \& Adolphe, L. (2013). Análise do impacto da morfologia urbana na demanda estimada de energia das edificações: um estudo de caso na cidade de Maceió, AL. Ambiente Construído, 13(4), 213233. http://dx.doi.org/10.1590/S1678-86212013000400015.

Mascaró, J. (2010). O custo das decisões arquitetônicas (5. ed.). Porto Alegre: Masquatro.

Nakano, A. K. (2018). A produção da “Cidade Oca” nos padrões recentes de verticalização e adensamento construtivo do município de São Paulo. Oculum Ensaios, 15(1), 33-50. http://dx.doi.org/10.24220/2318$0919 v 15 n 1 a 3373$.

Nogueira, A. M. P., Araújo, I. Á. L., Bittencourt, L. S., \& Restaino, G. (2018). Impacto da verticalização no microclima urbano: o caso do bairro Guaxuma, em Maceió-AL, Brasil. PARC Pesquisa em Arquitetura e Construção, 9(2), 72-85. http://dx.doi.org/10.20396/parc.v9i2.8650267.

Oliveira, T., Neumann, M., \& Wieczorek, L. (2018). Verticalização urbana: um quantitativo de edificações verticais na rua do comércio. Revista CIATEC-UPF, 10(1), 86-94. http://dx.doi.org/10.5335/ciatec.v10i1.6563.

Passo Fundo. (2006, 9 de outubro). Lei complementar n. 170, de 9 de outubro de 2006. Dispõe sobre o plano diretor de desenvolvimento integrado - PDDI do município de Passo Fundo. Passo Fundo: Diário Oficial. Recuperado em 10 de agosto de 2018, de https://leismunicipais.com.br/plano-diretor-passo-fundo-rs.pdf

Passo Fundo. (2020). Revisão do Plano Diretor. Recuperado em 26 de abril de 2020, de http://www.pmpf.rs.gov.br/secretaria.php?c=1353

Paula, K. A. (2019). O processo de verticalização na zona central da cidade de Viçosa-MG: uma análise a partir da expansão da Universidade Federal de Viçosa e do seu impacto na estruturação do espaço urbano. GeoTextos, 15(1), 65-87. http://dx.doi.org/10.9771/geo.v15i1.30473.

Rego, R. L., \& Meneguetti, K. S. (2011). A respeito da morfologia urbana: tópicos básicos para estudos da forma da cidade. Acta Scientiarum. Technology, 33(2), 123-127. http://dx.doi.org/10.4025/actascitechnol.v33i2.6196.

Scussel, M. C. B., \& Sattler, M. A. (2010). Cidades em (trans)formação: impacto da verticalização e densificação na qualidade do espaço residencial. Ambiente Construído, 10(3), 137-150. http://dx.doi.org/10.1590/S167886212010000300009.

Silva, G. J. A., \& Romero, M. A. B. (2013). Cidades sustentáveis: uma nova condição urbana a partir de estudos aplicados a Cuiabá, capital do estado de Mato Grosso, Brasil. Ambiente Construído, 13(3), 253-266. http://dx.doi.org/10.1590/S1678-86212013000300015.

Silva, I., Santos, R., Lopes, A., \& Araújo, V. (2018). Morphological indices as urban planning tools in northeastern Brazil. Sustainability, 10(12), 4358. http://dx.doi.org/10.3390/su10124358. 
Vargas, H., \& Araujo, C. (2014). Arquitetura e mercado imobiliário. São Paulo: Manole.

Vilela, J., Durante, L. C., \& Amorim, A. E. B. (2017). Morfologia urbana e propagação do ruído: influência do gabarito e de elementos arquitetônicos. In Anais do XIV Encontro Nacional de Conforto no Ambiente Construído

(ENCAC)/Encontro Latino-Americano de Conforto no Ambiente Construído (ELACAC) (pp. 1750-1759). Balneário Camboriú: ANTAC.

Editor: Rodrigo Firmino

Recebido: Dez. 14, 2019

Aprovado: Jul. 03, 2020 